\title{
OPTIMAL LOAD SCHEDULING OF NIGERIAN POWER SYSTEM WITH VALVE POINT EFFECT USING JAYA OPTIMIZATION ALGORITHM
}

\author{
V. K. Abanihi ${ }^{1, *}$ and J. N. Ndunagu ${ }^{2}$

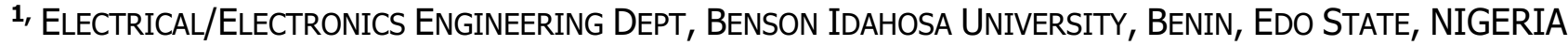

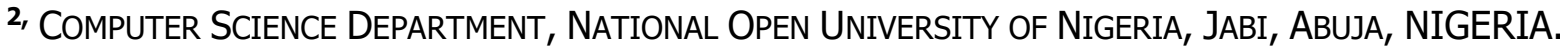 \\ E-mail addresses: ${ }^{1}$ vabanihi@biu.edu.ng, ${ }^{2}$ jndunagu@noun.edu.ng
}

\begin{abstract}
Economic load dispatch is a non-linear optimization problem which is of great importance in power systems. This paper proposes the optimal scheduling of the Nigeria Integrated Power System considering valve point loading effect using Jaya Optimization Algorithm (JOA). Data was collected from national control centre Osogbo and was used to develop cost function for the thermal stations actively contributing power to the national grid. M file was written in MatLab R2012a environment using Jaya Optimization Algorithm, Pattern Search Algorithm (PSA) and Genetic Algorithm (GA) to optimally schedule power generation by the power system. Result obtained showed that scheduling with JOA produced a cost of $210.8092 \mathrm{~N} / \mathrm{hr}$, PSA produced a cost of $211.9579 \mathrm{~N} / \mathrm{hr}$ and GA produced a cost of $212.6687 \mathrm{~N} / \mathrm{hr}$. The simulation result shows the advantage of the proposed method for reducing the total cost of power generation by the system over the other methods.
\end{abstract}

Keywords: load scheduling, value point, Jaya optimization, pattern search, genetic algorithm

\section{INTRODUCTION}

Optimal Generation Scheduling (OGS) which can also be referred to as Economic Load Dispatch (ELD) in power system, is a constraint based optimization problem in power system that has the objective of dividing the total power demand among the online participating generators economically (optimally) while satisfying the essential constraints [1 - 4]. The conventional methods that have been used to solve this problem includes the Unconstrained Optimization methods, Linear Programming and Dynamic Programming, Newton's method and Interior Point method [5].

Other Artificial Intelligence (AI) based methods have been proposed for solving Optimal Generation Scheduling (OGS) problem such as Genetic Algorithm (GA) [6, 7], Tabu Search Algorithm (TSA) [8], Particle Swarm Optimization (PSO) $[9,10]$ Artificial Neural Network (ANN) [11], Evolutionary Programming (EP) [12] and Artificial Bee Colony (ABC) [5].

Electricity supply in Nigeria is epileptic, total power generated cannot meet the demand of the ever growing consumers. Investors have constantly moved to other countries because of the epileptic nature of power supply in Nigeria which has led to loss of job and the economy not developing at the rate it is supposed to $[10,13]$. The power generating stations in the country are located at different point which are far from each other, some of the power stations are very old while some are new, which means they cannot have the same cost functions [14]. Also ageing infrastructure, weak and radial network instead of ring main configuration, and overloaded transformers leads to frequent system collapse, with high transmission and distribution losses and poor voltage profile [13]. Considering the above mentioned problems, it becomes necessary for us to study the cost functions of the integrated thermal generating stations, their power limits and the maximum power demand of the whole country so as to schedule generation effectively.

This paper proposes JOA as an optimization technique to optimally schedule the thermal power generating stations in the country and solve constraints based quadratic cost function with generator constraints. Results obtained are compared with GA and SA

* Corresponding author tel: $+\mathbf{2 3 4}-\mathbf{8 0 3}-\mathbf{4 1 0}-2488$ 
methods. The proposed methodology emerges as robust optimization techniques for solving the OGS problem for the Nigerian power system.

\section{PROBLEM FORMULATION}

The classic optimal generation scheduling problem minimizes the following incremental fuel cost function associated to the individual thermal power generating stations [15];

$$
C_{T}=\sum_{i=1}^{N} C_{i}\left(P_{i}\right)
$$

The cost characteristic are shown as

$$
C_{i}=\alpha_{i} P_{i}^{2}+\beta_{i} P_{i}+\gamma_{i} \$ / h r
$$

Where $a_{i}, \beta_{i}$ and $\gamma_{i}$ are constants.

\subsection{Equality Constraints:}

The real power balance in the system is given by

$$
\sum_{i=1}^{N} P_{G i}=P_{d}+P_{\text {loss }}
$$

Where Ploss calculated using the B-Matrix loss coefficients and expressed in the quadratic form as given below:

$$
P_{\text {loss }}=\sum_{i=1}^{n} \sum_{j=1}^{n} P_{i} B_{i j} P_{j}
$$

Where $B_{i j}$ is loss coefficient.

\subsection{Inequality Constraints:}

The generation power ' $P$ ' cannot be outside the range stated by the inequality

$$
P_{i \min } \leq P \leq P_{i \max }
$$

Where $C_{T}$ total production cost $(R s / h) ; C_{i}\left(P_{i}\right)$, is incremental fuel cost function $(\mathrm{Rs} / \mathrm{h}) ; \mathrm{P}_{\mathrm{i}}$, is real power output of the $i^{\text {th }}$ unit (MW); $N$ is number of generating units; $P_{d}$ is power demand (MW); $P_{\text {loss }}$ is power loss (MW); $B_{i j}$ is transmission loss coefficients; $P_{i m i n}$ is minimum limit of the real power of the $i^{\text {th }}$ unit (MW); Pimax is maximum limit of the real power of the $i^{\text {th }}$ unit (MW) $[15-18]$.

The problem of optimal generation scheduling of real power is to be done to the required load demand by satisfying the above constrains.

\subsection{Valve-Point Loading Effect}

For more rational and precise modelling of fuel cost function, the above expression of cost function is to be modified suitably. The generating units with multivalve steam turbines exhibit a greater variation in the fuel-cost functions [18]. The valve opening process of multi-valve steam turbines produces a ripple-like effect in the heat rate curve of the generators. These "valve-point effects" are illustrated in Figure-1 [19 21].

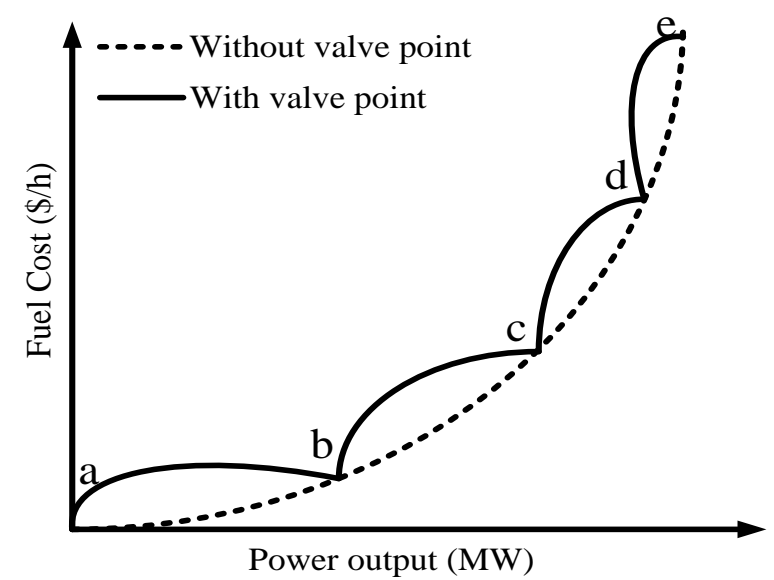

Figure 1: Valve Point loading effect

The significance of this effect is that the actual cost curve function of a large steam plant is not continuous bur more important it is non-linear. In reality, the generating units with multi-valve steam turbine have very different input-output curve compared with the smooth cost function. Therefore, the representation of the incremental fuel cost function of the generating units more practical. The incremental fuel cost function of a generating unit with valve-point loadings is represented as Equation (6).

$$
\begin{aligned}
C_{i}=\alpha_{i} P_{i}^{2}+\beta_{i} P_{i} & +\gamma_{i} \\
& +\left|e_{i} \times \sin f_{i} \times\left(P^{\text {min }}-P_{i}\right)\right| \$ / h r
\end{aligned}
$$

Where $e_{i}$ and $f_{i}$ are the coefficients of generator reflecting the valve-point effects $[19-21]$.

\section{JAYA OPTIMIZATION ALGORITHM}

Jaya optimization algorithm is a simple but powerful optimization algorithm developed by Dr. R. Venkata Rao in 2015 for solving the constrained and unconstrained optimization problems [22]. This algorithm is based on the concept that the solution obtained for a given problem should produce the best solution and should not produce the worst optimal solution. This algorithm requires only the common control parameters and does not require any algorithm-specific control parameters.

Let $f(x)$ is the objective function to be minimized (or maximized). At any iteration $\mathrm{I}$, assume that there are ' $m$ ' number of design variables (i.e. $j=1,2 \ldots m$ ), ' $n$ ' number of candidate solutions (i.e. population size, $\mathrm{k}$ $=1,2, \ldots, n)$. Let the best candidate obtains the best 
value of $f(x)$ (i.e. $f(x)$ best) in the entire candidate solutions and the worst candidate worst obtains the worst value of $f(x)$ (i.e. $f(x)$ worst) in the entire candidate solutions. If $\mathrm{Xj}, \mathrm{ki}$ is the value of the jth variable for the kth candidate during the ith iteration then this value is modified as per the following Equation [23].

$$
\begin{aligned}
X_{j, k, i}^{\prime}=X_{j, k, i}+r_{j, k, i}( & \left.X_{j, b e s t, i}-\left|X_{j, k, i}\right|\right) \\
& -r_{2, j, i}\left(X_{j, w o r s t, i}-\left|X_{j, k, i}\right|\right)
\end{aligned}
$$

$X_{j, \text { best, }}$ - the value of the variable $j$ for the best candidate

$\mathrm{X}_{\mathrm{j}, \text { worst, } \mathrm{i}}$ - is the value of the variable $\mathrm{j}$ for the worst candidate,

$X_{1 j, k, r}$ is the updated value of $X_{j, k, i}$

$r_{1, j, j}$ and $r_{2, j, i}$ - are the two random numbers for the $j^{\text {th }}$ variable during the $i^{\text {th }}$ iteration in the range $[0,1]$.

$r_{1, j, i}\left(X_{j, b e s t, i}-\left|X_{j, k, i}\right|\right)$ - indicates the tendency of the solution to move closer to the best solution.

$\mathrm{r}_{1, j, \mathrm{i}}\left(\mathrm{X}_{\mathrm{j}, \text { worst,i }}-\mid \mathrm{X}_{\mathrm{j}, \mathrm{k}, \mathrm{i}}\right)$ - indicates the tendency of the solution to avoid the worst solution. $X_{1 j, k, i}$ is accepted if it gives better function value.

All the accepted function values at the end of iteration are maintained and these values become the input to the next iteration. The algorithm always tries to get closer to success (i.e. reaching the best solution). The algorithm strives to become victorious by reaching the best solution and hence it is named as Jaya $[17,22$, 23].

\section{RESULT AND DISCUSSION}

The cost function of the Nigerian Integrated thermal generating stations were used in the total fuel cost. The cost functions of the thermal stations, their maximum and minimum power limits with valve point effects based on data obtained from the National control centre Osogbo are given in Table 1 [16]. The load demand to be satisfied was 3500 MW (without considering transmission losses). To find the optimal scheduling for the Nigerian power system, the following techniques have been utilized: Jaya Optimization Algorithm, Genetic Algorithm (GA) and Pattern Search Algorithm (PSA). The population size, maximum and minimum generation limits and iteration count for the power system was fixed. The results for the power system applying JOA, GA and PSA are shown in Table 2. The programs were written and ran in MATLAB environment. According to the constraints considered in this work among inequality constraints only active power constraints are considered. There operating limit of maximum and minimum power are also different. The unit operating ranges given in the Table 1 [16] i.e. $P_{i}^{\min } \leq P_{i} \leq P^{\max }$.

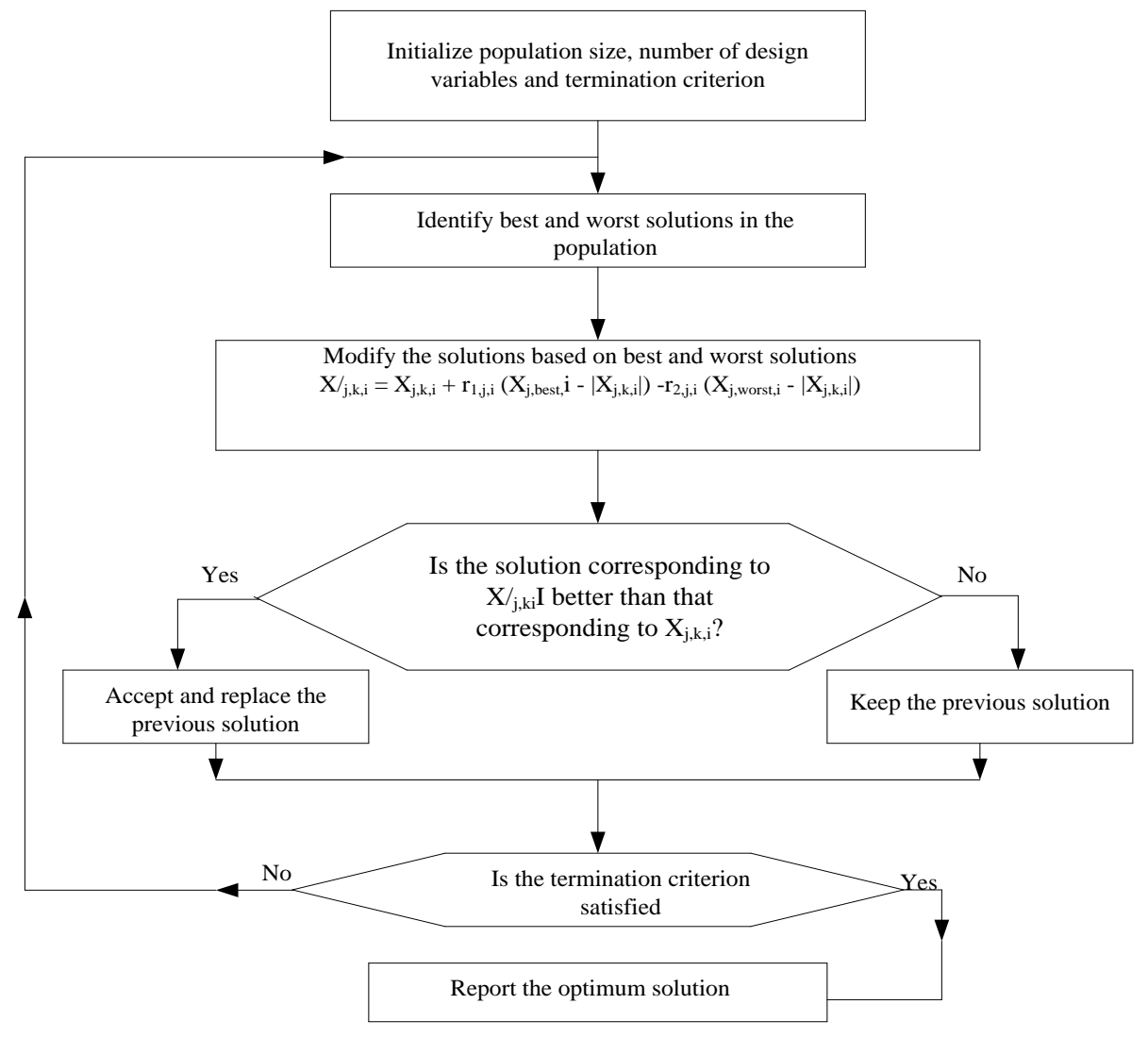

Figure 2: Flow Chart of Jaya Optimization Algorithm 
Table 1: Data for Nigerian Integrated thermal power stations.

\begin{tabular}{ccccccccc}
\hline $\mathrm{S} / \mathrm{N}$ & Power Stations & $\mathrm{ai}_{\mathrm{i}}$ & $\mathrm{b}_{\mathrm{i}}$ & $\mathrm{Ci}_{\mathrm{i}}$ & $\mathrm{ei}_{\mathrm{i}}$ & $\mathrm{fi}_{\mathrm{i}}$ & $\mathrm{P}_{\mathrm{in}}^{\text {min }}$ & $\mathrm{P}_{\mathrm{i} \text { max }}$ \\
\hline 1 & EGBIN ST(GAS) & 0.0000109 & 0.0284 & 3.92 & 310 & 0.0086 & 118 & 1100 \\
2 & SAPELE ST & 0.0000591 & 0.0226 & 8.10 & 200 & 0.0042 & 33 & 223 \\
3 & DELTA II-III & 0.0000757 & 0.0326 & 6.47 & 80 & 0.0098 & 10 & 110 \\
4 & DELTA IV & 0.0000743 & 0.0334 & 9.85 & 230 & 0.0047 & 22 & 434 \\
5 & GEREGU & 0.0000201 & 0.0313 & 1.25 & 270 & 0.0037 & 14 & 450 \\
6 & OMOTOSHO & 0.0000514 & 0.0312 & 4.70 & 280 & 0.0039 & 29 & 480 \\
7 & OLORUNSOGO & 0.0000294 & 0.0313 & 2.80 & 210 & 0.0043 & 10 & 293 \\
8 & AFAM IV-V & 0.0000834 & 0.0289 & 2.03 & 271 & 0.0048 & 24 & 453 \\
9 & SAPELE GT NIPP & 0.0000105 & 0.0227 & 5.60 & 211 & 0.0044 & 30 & 373 \\
10 & ALAOJI NIPP & 0.0000200 & 0.0332 & 3.00 & 120 & 0.0077 & 34 & 87 \\
11 & GEREGU NIPP & 0.0000223 & 0.0314 & 1.00 & 190 & 0.0039 & 94 & 272 \\
12 & OLORUNSOGO NIPP & 0.0000287 & 0.0313 & 1.70 & 225 & 0.0046 & 31 & 422 \\
13 & OMOTOSHO NIPP & 0.0000179 & 0.0313 & 2.64 & 185 & 0.0045 & 20 & 225 \\
14 & IHOVBE NIPP & 0.0000200 & 0.0294 & 1.00 & 80 & 0.0098 & 91 & 120 \\
15 & OKPAI & 0.0000326 & 0.0286 & 4.53 & 292 & 0.0034 & 100 & 475 \\
16 & AFAM VI & 0.0000115 & 0.0286 & 8.00 & 320 & 0.0036 & 45 & 656 \\
17 & AES & 0.0000133 & 0.0286 & 4.30 & 215 & 0.0043 & 51 & 242 \\
18 & OMOKU & 0.0000442 & 0.0314 & 1.30 & 112 & 0.0076 & 3 & 65 \\
19 & IBOM & 0.0000189 & 0.0312 & 4.60 & 80 & 0.0098 & 10 & 101 \\
20 & TRANS AMADI & 0.0000315 & 0.0311 & 1.00 & 67 & 0.0083 & 4 & 31 \\
21 & RIVERS IPP & 0.0000215 & 0.0318 & 6.00 & 120 & 0.0077 & 20 & 160 \\
\hline
\end{tabular}

Table 2: ELD with valve point effect neglecting loss

\begin{tabular}{|c|c|c|c|c|}
\hline \multirow{2}{*}{$S / N$} & \multirow{2}{*}{ Power Stations } & \multicolumn{3}{|c|}{ Method of Optimization } \\
\hline & & JOA & PSA & GA \\
\hline 1. & EGBIN ST (GAS) & 278.8012 & 352.4037 & 605.3239 \\
\hline 2. & SAPELE ST & 39.6827 & 40.4529 & 185.8841 \\
\hline 3. & DELTA \|-III & 52.3329 & 103.8878 & 98.9096 \\
\hline 4. & DELTA IV & 77.7609 & 307.3493 & 84.1693 \\
\hline 5. & GEREGU & 281.0872 & 28.3088 & 360.2352 \\
\hline 6. & OMOTOSHO & 379.0098 & 76.353 & 181.1366 \\
\hline 7. & OLORUNSOGO & 81.8758 & 272.045 & 232.2028 \\
\hline 8. & AFAM IV-V & 183.7561 & 240.1686 & 156.3046 \\
\hline 9. & SAPELE GT NIPP & 228.7876 & 346.7002 & 140.6664 \\
\hline 10. & ALAOJI NIPP & 45.6829 & 84.2063 & 44.4524 \\
\hline 11 & GEREGU NIPP & 186.1249 & 169.4776 & 136.9487 \\
\hline 12 & OLORUNSOGO NIPP & 312.9043 & 264.9911 & 418.4326 \\
\hline 13 & OMOTOSHO NIPP & 38.6737 & 171.7743 & 194.2104 \\
\hline 14 & IHOVBE NIPP & 120 & 91.7641 & 93.2798 \\
\hline 15 & OKPAI & 297.6855 & 122.4395 & 113.4729 \\
\hline 16 & AFAM VI & 531.7802 & 419.4505 & 74.8461 \\
\hline 17 & AES & 168.813 & 240.9073 & 171.6475 \\
\hline 18 & OMOKU & 22.1318 & 11.4436 & 8.7339 \\
\hline 19 & $\mathrm{IBOM}$ & 39.2315 & 64.326 & 53.3774 \\
\hline 20 & TRANS AMADI & 26.9677 & 16.91 & 8.6454 \\
\hline 21 & RIVERS IPP & 106.9102 & 74.6404 & 137.1203 \\
\hline & TOTAL COST(N/hr) & 210.8092 & 211.9579 & 212.6687 \\
\hline & ITERATION & 90 & 220 & 310 \\
\hline
\end{tabular}


To investigate the effectiveness of the proposed JOA, Genetic Algorithm (GA) and Pattern Search Algorithm have been considered for the purpose of comparison. The outputs using all the three algorithms have been shown in Table 2. It is seen that the results obtained from JOA are almost same with the results of the other two methods, but the JOA have shown superiority over the other two methods. The minimum cost obtained by JOA is $210.8092 \mathrm{~N} / \mathrm{hr}$ and converged after 90 iterations, the minimum cost for PSA is $211.9579 \mathrm{~N} / \mathrm{hr}$ and converged after 220 iterations and the minimum cost for GA is $212.6687 \$ / \mathrm{hr}$ and converged after 310 iterations. The results demonstrate that the proposed algorithm outperforms the other methods in terms of optimal solutions. In table 2 the optimal value of power generation with the effect of valve point is achieved using JOA within the operating limit as given in Table 1. Hence, with the help of these optimized value of power generations which meets $3500 \mathrm{MW}$ demand we able to obtain the optimum minimum cost of total generation. The convergence profile of the cost function is depicted in Fig 3, optimal generation scheduling of the Nigerian Integrated Power System shown in the Fig 4.

\section{CONCLUSION}

The optimum cost for the Nigerian Integrated Power System with valve point effect is achieved by JOA and after comparing with GA and PSA it is found that the proposed algorithm outperforms the other methods in terms of better optimal solution and the best ELD solutions obtained by the proposed method for the load demand of $3500 \mathrm{MW}$. The performance of JOA proved to be effective while satisfying the constraints with highly probable solutions in an acceptable computing time. Jaya Optimization Algorithm has therefore proved to be the very effective technique to solve Economic Load Dispatch problem with valvepoint consideration.
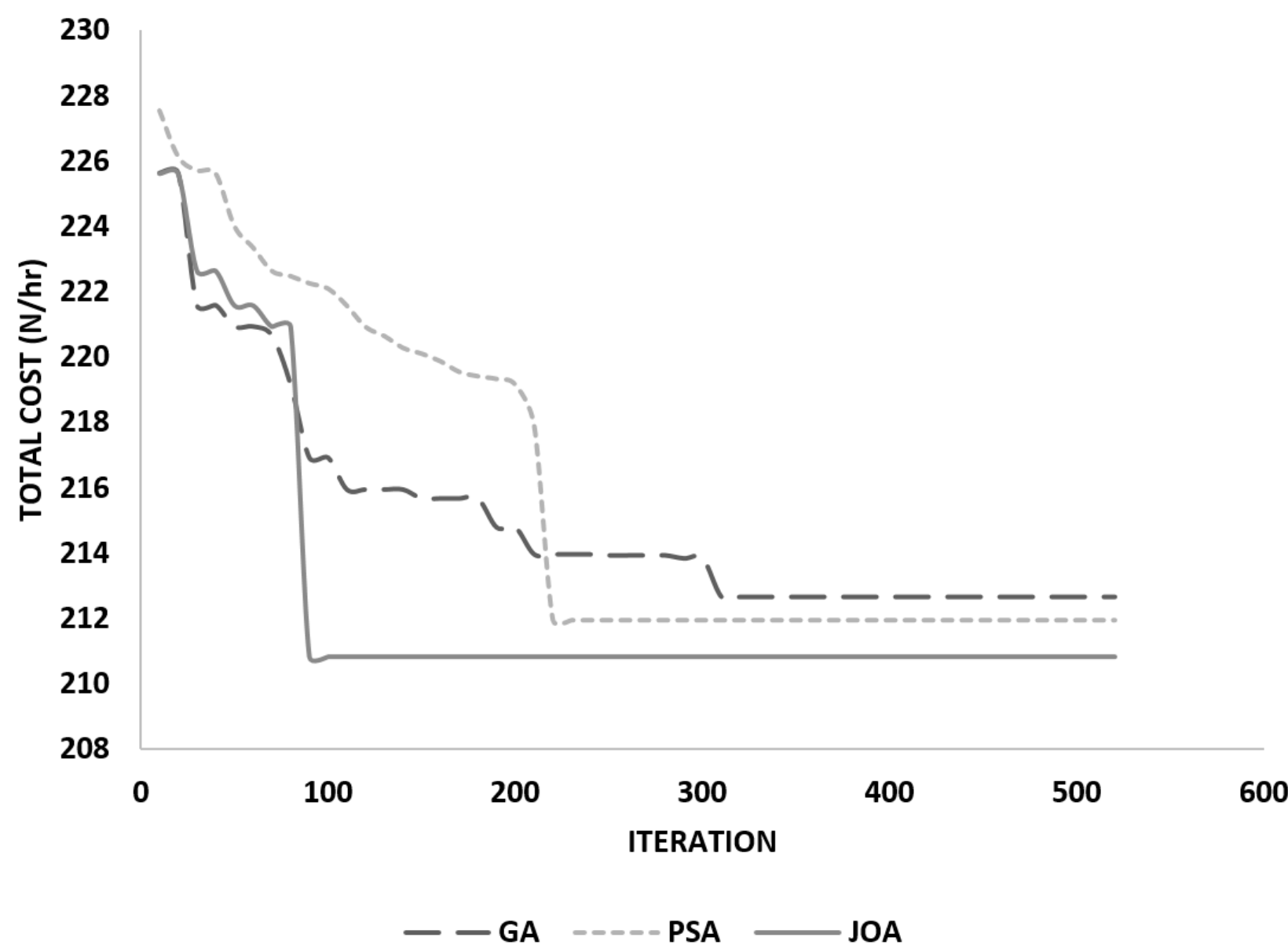

Figure 3: Cost curve of 3500 MW demand by JOA method with valve point effect without loss 


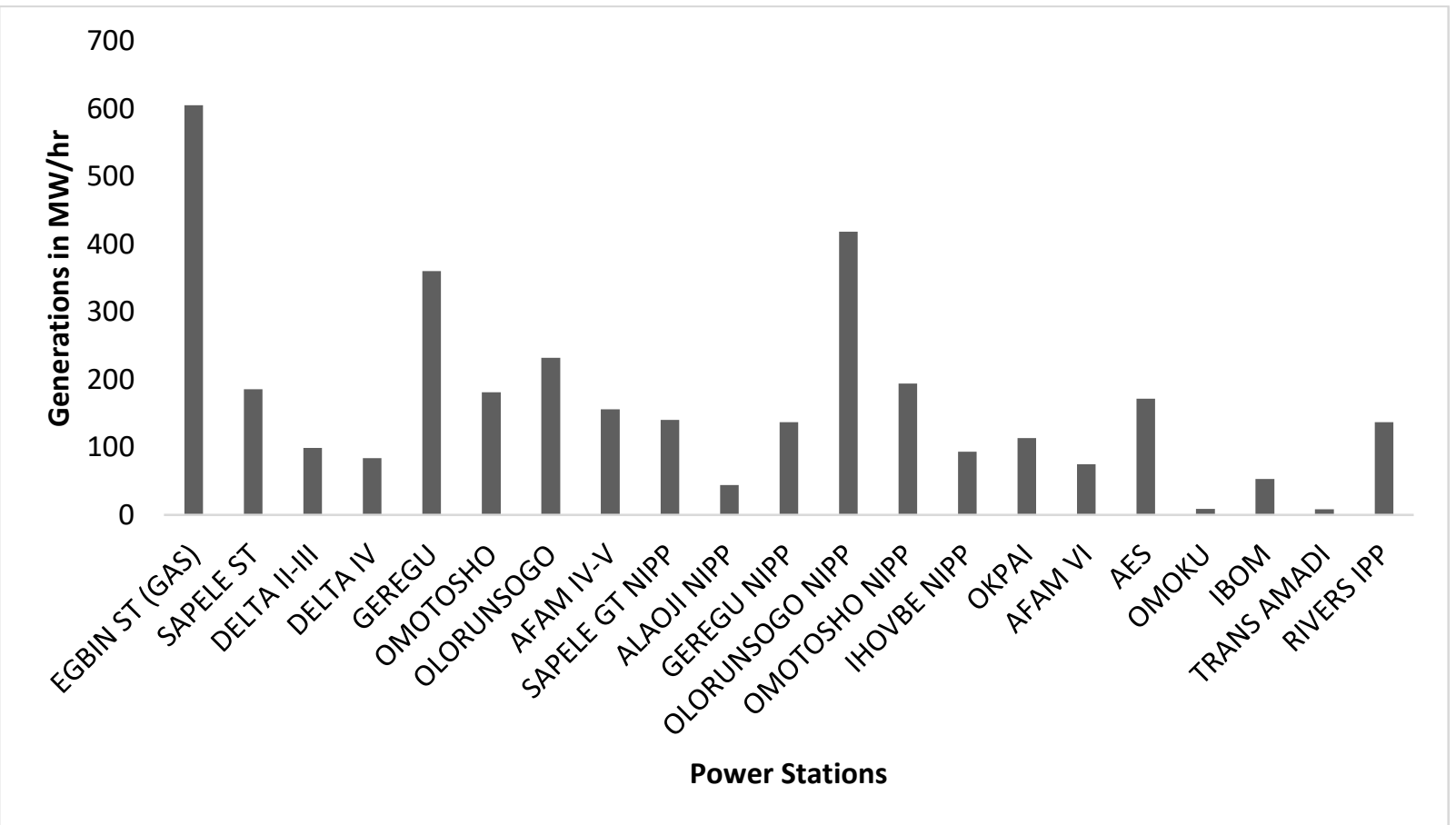

Figure 4: Optimal Generation Scheduling of 3500 MW demand by JOA method with valve point effect without loss

\section{REFERENCES}

[1] Preeti, P., Prakash, R. and Anguraja, R. "Economic Load Dispatch Optimization Using Gat Algorithm with Various Percentages of Loads at Different Time Intervals", International Journal of Recent Trends in Engineering and Research, vol. 3 no 4, pp.322 - 326, 2017.

[2] Wulandhari, L. A., Komsiyah, S. and Wicaksono, W. "Bat Algorithm Implementation on Economic Dispatch Optimization Problem", Issue 135, pp. 275 - 282, 2018.

[3] Nguyen, T. T. and Ho, S. D. "Bat Algorithm for Economic Emission Load Dispatch," International Journal of Advanced Science and Technology, vol. 86, pp.51-60, 2016.

[4] Dao, T., Pan, T., Nguyen, T. and Chu, S. "Evolved Bat Algorithm for Solving the Economic Load Dispatch Problem," Advances in Intelligent Systems and Computing, Issue 329, pp.109 -119, 2015.

[5] Vijay, R. and Ravichandran, C. S. "A Detailed Investigation on Conventional and Meta-Heuristic Optimization Algorithms for Economic Power Scheduling", International Journal of Engineering Tends and Applications, vol. 3 no. 4, pp.40 - 53, 2016.

[6] Singh, S. P., Tyagi, R. and Goel, A. "Genetic Algorithm for Solving the Economic Load
Dispatch" International Journal of Electronic and Electrical Engineering, vol. 7 no. 5 pp. 523 - 523, 2014.

[7] Sahu, B., Lall, A., Das, S. and Patra, T. M. "Economic Load Dispatch in Power System using Genetic Algorithm", International Journal of Computer Applications, vol. 67 no. 7, pp.17 - 22, April 2013.

[8] Bakhta, N., Hamid, B. and Ahmed, A. "Solving the Economic Dispatch Problem by Using Tabu Search Algorithm," Elsevier Advancements in Renewable Energy and clean Environment, Issue 36 pp.694 - 701, 2013.

[9] Sarma, J. and Mahor, A. "Particle Swarm Optimization Approach for Economic Load Dispatch: Review", International Journal of Engineering Research and Applications, vol. 3 no 1 pp.13 - 22, Feb. 2013.

[10] Haruna, Y. S., Yisah, Y. A., Bakare, G. A., Haruna, M. S. and Oodo, S. O. "Optimal Economic Load Dispatch of the Nigerian Tharmal Power Stations Using Particle Swarm Optimization (PSO)", The International Journal of Engineering and Science, vol. 6 no. 1, pp.17 - 23, 2017.

[11] Mathur, S., Joshi, S. K. and Joshi, G. K. "Economic Load Dispatch by Generating Units under Varying Load Demands Using Artificial Neural Network", International Journal on 
Computer Science and Engineering, vol. 5 no. 7, pp.639-647, 2013.

[12] Sayah, S. and Zehar, K. "Using Evolutionary Computation to Solve the Economic Load Dispatch Problem" Leonardo Journal of Sciences. Issue 12, pp.67 - 78, 2008.

[13] Onohaebi, S. O. and Omorogiuwa, E. "Smart Grid and Energy Management in Nigeria Integrated Power System", International Journal of Engineering Innovation and Research, vol. 3 no. 6, pp.732 - 743, 2014.

[14] Buraimoh, E., Ejidokun, T. O. and Ayamolowo, O. J. "Optimization of an Expanded Nigeria Electricity Grid System using Economic Load Dispatch," Abuad Journal of Engineering Research and Development, vol. 1, no. 1, pp.61 - 66, Oct. 2017.

[15] Haruna, Y. S., Idris, S., Bakare, G. A. and Abu, A. U. "Comparative Analysis of the Economic Load Dispatch Problem of the Nigerian Thermal Power Stations", Global Scientific Journals, vol. 6 no. 4, pp. 243 - 251, April 2018.

[16] Abanihi, V. K. "Economic Load Dispatch of Nigerian High Voltage Generation and Transmission Grid," PhD thesis, Department of Electrical/Electronic Engineering, University of Benin, Benin City, 2016.

[17] Yadav, R. K. and Kaurav, M. S. "Solving Economic Load Dispatch Problem with Valve Point Effect", International Research Journal of Engineering and Technology, vol. 5 no. 11, pp. 1481 - 1485, Nov. 2018.
[18] Nawaz, A., Saleem, N., Mustafa, E. and Khan, U. A. "An efficient global technique for Solving the Network Constrained Static and Dynamic Economic Dispatch Problem," Turkish Journal of Electrical Engineering and Computer Sciences, Issue 25, pp.73-82, 2017.

[19] Ajenikoko, G. A., Olaniyan, O. S. and Adeniran, J. O. "Cuckoo Search Algorithm Optimization Approaches for Solving Economic Load Dispatch: A Review," Journal of Energy Research and Reviews, vol. 1 no. 2, pp1 - 15, 2018.

[20] Gautham, S. and Rajamohan, J. "Economic Load Dispatch using Novel Bat Algorithm" $1^{\text {st }}$ IEEE International Conference on Power Electronics, Intelligent Control and Energy Systems, 2016.

[21] Olakunle, A. O. and Folly, K. A. "Economic Load Dispatch of Power System Using Genetic Algorithm with Valve Point Effect", Springer International Publishing Switzerland, pp.276 284, 2015.

[22] Rao, R. V. "A Simple and New Optimization Algorithm for Solving Constrained and Unconstrained Optimization Problems," International Journal of Industrial Engineering Computations, Issue 7, pp.19-34, 2016.

[23] Banerjee, S. and Sarkar, D. "Comparative Analysis of Jaya Optimization Algorithm for Economic Dispatch Solution," International Journal for Research in Applied Science and Engineering Technology, vol. 5 no. 8 pp.909 922, 2017. 